\title{
IoT Based Access Control Mechanism Using RFID Technology
}

\author{
M. Swathika ${ }^{1}$ and G. Indirani ${ }^{2}$ \\ ${ }^{1}$ PG Student, Department of Electronics and Instrumentation Engineering, Annamalai University, Tamil Nadu, India \\ ${ }^{2}$ Assistant Professor, Department of Computer Science Engineering, Annamalai University, Tamil Nadu, India \\ E-Mail: swathikamuthu20@gmail.com,induk0992@gmail.com
}

\begin{abstract}
Internet of Things plays a vital role in day to day life of this developing technological world. IoT involves many technologies such as RFID technology, sensor technology, smart technology, Nano technology etc. IoT based RFID technology is studied in this paper. The introduction about IoT is firstly presented. Then, the RFID technology-Radio Frequency Identification Technology and its components are explained. Then, the interfacing of RFID-RC522 with Arduino Uno and the interfacing of wifi module ESP8266 with Arduino Uno are mentioned. Then, the overall procedure of using RFID for security purpose is explained with flow diagram. For this security system, the output of accessing certain number of selected tags and denying all other tags is obtained. Some applications related to IoT based security system using RFID technology are attached. Finally, the output is discussed in conclusion part. We believe that the RFID technology will be developed further and innovated to provide many applications and services for users in the future.

Keywords: Internet of Things, Radio Frequency Identification Technology, RFID-RC522, ESP8266
\end{abstract}

\section{INTRODUCTION}

Internet of Things is the network of physical devices, vehicles, home appliances and other things that are embedded with electronics, software, sensors, actuators and connectivity(Internet) through which we can connect these things and exchange data between them. In IoT, the things we are using in our day to day life can be connected via internet so that we can develop many applications by monitoring and controlling them without any distance limits.

\section{RADIO FREQUENCY IDENTIFICATION TECHNOLOGY}

Radio Frequency Identification (RFID) consists of a tag or label and a reader. RFID technology uses radio frequency electromagnetic fields to transmit and receive information to and from the tag by the reader. The tag can be attached to any object that is to be monitored or controlled.

\section{A. RFID System Components}

1. RFID Reader: The RFID reader can read the data from the RFID tag using radio frequency electromagnetic fields. The RFID reader and pin header are represented in Fig. 1.
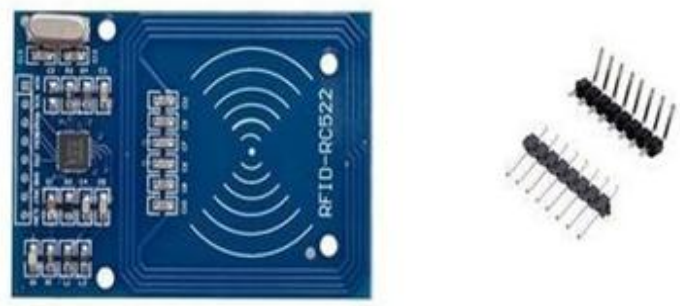

Fig. 1 RFID reader and pin header

Here, the pin header is used to connect the RFID reader to Arduino board.

2. RFID Tags: The RFID tags include matching tag and non-matching tag (false tag). Each tag has its own UID Unique Identification Code. If the UID of the matching tag is included in the uploading program of Arduino Uno, then the reader will accept only when the matching tag is kept closer to it. And the non-matching or false tag will be denied when it is kept closer to the reader. The matching tag and false tag are represented in Fig. 2 and Fig. 3 respectively.

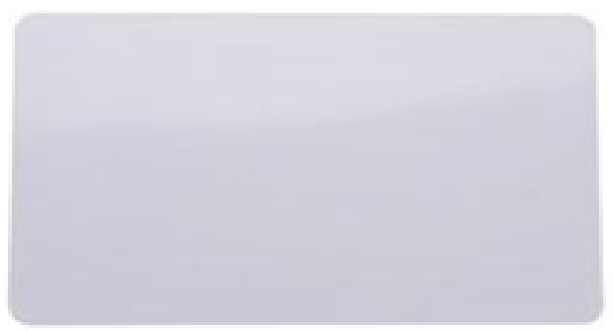

Fig. 2 Matching tag

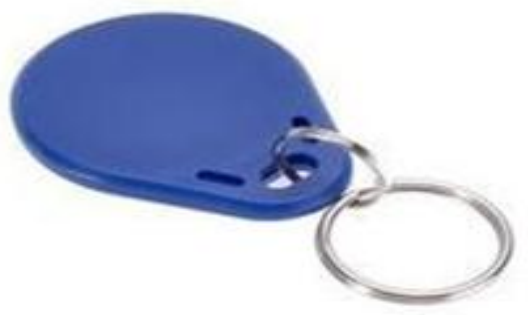

Fig. 3 False tag (Non-matching tag) 
Any of these two tags can be chosen as matching or nonmatching tag. The only thing is the UID of the chosen matching tag is included as the matching tag UID in the uploading program. The RFID used in this paper is RFIDRC522.

\section{INTERFACING RFID-RC522 WITH ARDUINO UNO}

The RFID-RC522 is interfaced with Arduino Uno either directly or using breadboard. The interfacing is shown in Fig.4. And the pin connections are represented in Table I.

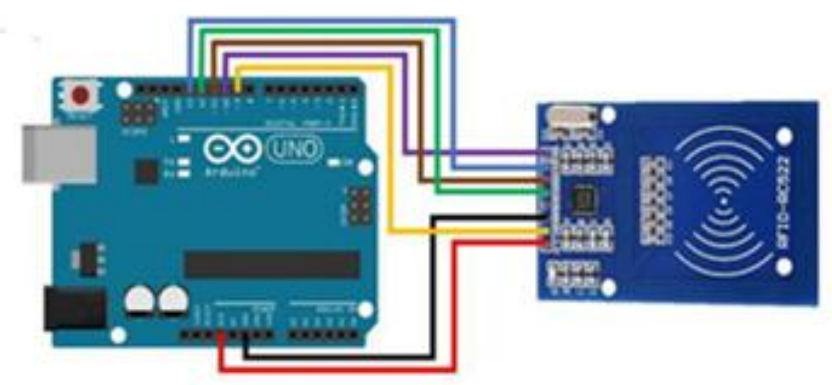

Fig. 4 Interfacing RFID-RC522 with Arduino Uno

TABLE I PIN CONNECTIONS FOR INTERFACING RFID-RC522 WITH ARDUINO UNO

\begin{tabular}{|c|c|c|}
\hline S. No. & RFID-RC522 pin & Arduino pin \\
\hline 1 & SDA & Digital 10 \\
\hline 2 & SCK & Digital 13 \\
\hline 3 & MOSI & Digital 11 \\
\hline 4 & MISO & Digital 12 \\
\hline 5 & IRQ & Unconnected \\
\hline 6 & GND & GND \\
\hline 7 & RST & Digital 9 \\
\hline 8 & $3.3 \mathrm{~V}$ & $3.3 \mathrm{~V}$ \\
\hline
\end{tabular}

\section{INTERFACING ESP8266 WITH ARDUINO UNO}

The ESP8266 is a wifi module which is interfaced with Arduino Uno to provide internet connection to the set up. The interfacing of ESP8266 and Arduino Uno is shown in Fig.5. And the pin connections are represented in Table II.

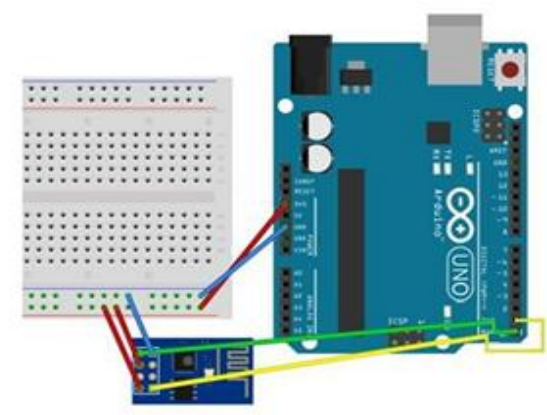

Fig. 5 Interfacing ESP8266 with Arduino Uno
TABLE II PIN CONNECTIONS FOR INTERFACING ESP8266 WITH ARDUINO UNO

\begin{tabular}{|c|c|c|}
\hline S. No. & ESP8266 pin & Arduino pin \\
\hline 1 & TX & RX \\
\hline 2 & RX & TX \\
\hline 3 & EN & $3 V 3$ \\
\hline 4 & $3 V 3$ & $3 V 3$ \\
\hline 5 & GND & GND \\
\hline
\end{tabular}

\section{OVERALL FLOWING STEPS}

The overall flow diagram for this analysis of access control mechanism is shown in Fig. 6.

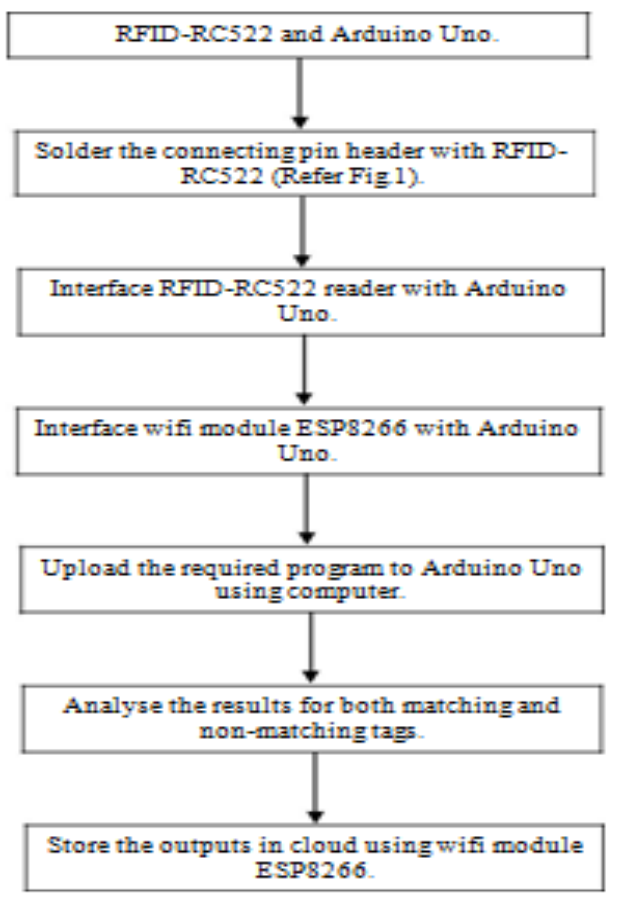

Fig. 6 Overall flow diagram for IoT based access control mechanism using RFID

1. To connect the RFID-RC522 and Arduino Uno, the connecting pin header is first soldered with RFIDRC522 and then the RFID-RC522 is interfaced with Arduino Uno.

2. Then, the wifi module ESP8266 is interfaced with Arduino Uno and the entire set up is represented in Fig. 7.

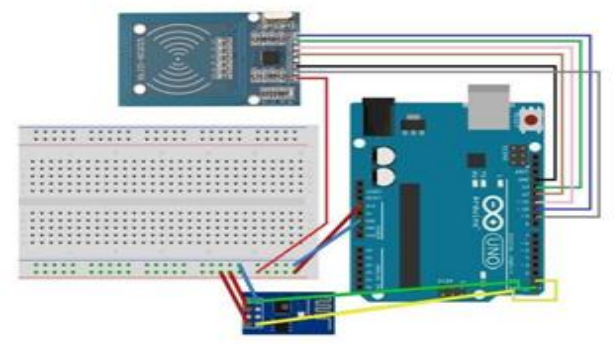

Fig. 7 The entire set up of Arduino Uno with RFID-RC522 and ESP8266 
3. The required program is uploaded to the Arduino Uno by a computer using USB cable.

4. After uploading the program, the RFID reader is ready to respond. In this paper, the white card is considered as matching tag and the blue tag is considered as false tag or non-matching tag.

5. The UID of the selected matching tag is included in the coding and so, the output is obtained as "Authorized access" in the serial monitor when the matching tag is kept closer to the reader. And when the false or nonmatching tag is kept closer to the reader, the output is obtained as "Access denied" in the serial monitor.

The output obtained for matching and non-matching tags is shown in Fig. 8.

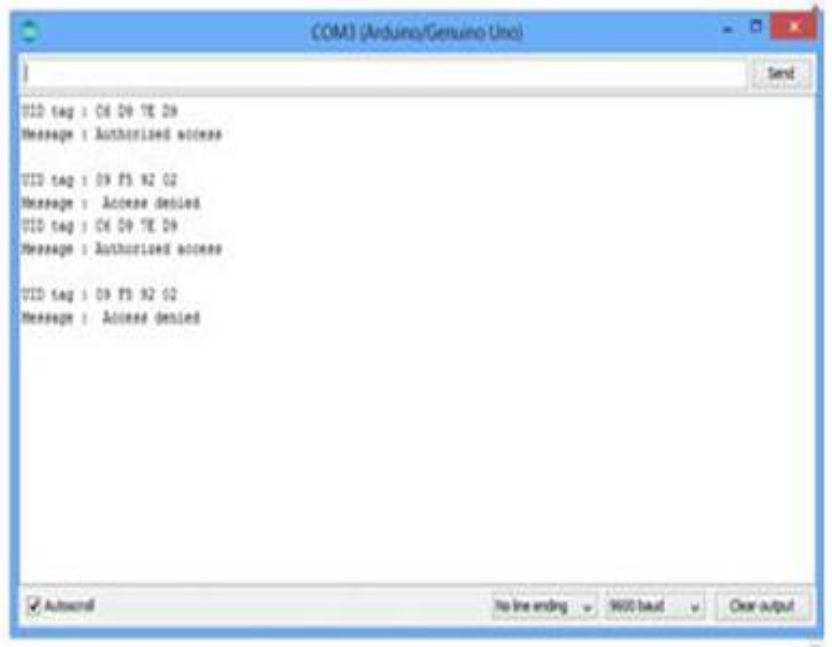

Fig. 8 The output obtained when matching and non-matching tags are kept closer to the reader

6. Likewise, many tags are considered as matching tags and the set of all their UIDs are included in the program. After uploading the program, the output is obtained as "Authorized access" when the considered matching tags are kept closer to the reader and "Access denied" for all other tags whose UIDs are not included in the coding.

7. Then the outputs are stored in cloud so that the data can be checked and analysed whenever necessary.

8. The analysis of these outputs shows that this setup can be used in many applications wherever proper security access is required. Because, only the selected tags are allowed to access and all other cards are automatically denied.

\section{APPLICATIONS}

Many applications and services are available based on this RFID technology. We can innovate and develop this IoT based RFID technology to introduce new applications in the future. Some of the RFID based applications are as follows.
A. RFID Based Security System: In this application, the system avoids the entry of unauthorized person to a highly secured area. The details of authorized person are stored in the microcontroller database and when he swipes his card, the reader gets the data and passes to the microcontroller. When the data matches with the stored data, the system allows the user to enter the area.

B. Attendance System: In this system, when the person swipes his card, the card receives a carrier signal from the reader and modulates it and sends back to the reader. When the signal matches with the stored data, the system accepts his thumb impression and provides attendance by displaying the status of the person.

C. Anti-Theft Auto Security System: In this application, even though the key matches the vehicle, the theft can be avoided by verifying the UID of the particular tag. When the UID mismatches the coded UID, the system integrated with ignition circuit, power control unit and automatic gear changing system reduces the speed of the vehicle to zero to keep the vehicle safer.

D. Automatic Door Lock System: In this system, the reader reads the data and sends to the controller. The controller verifies the data with the stored data and controls the opening and closing of the door according to the matching and mismatching of the data.

E. Automatic Car Parking: In this application, car parking is controlled by RFID technology. The car owners have to swipe the card to enter the parking area and the system produces a buzzer sound for each entry. For each entry, the available parking space reduces by one and for each exit, the available space increases by one.

\section{CONCLUSION}

Thus, the output obtained in this paper concludes that the process of accessing and denying can be controlled by RFID technology. In reference paper [3], they combined the RFID technology and biometrics to complete their task. Similarly, when the biometrics technology is included with the system proposed in this paper, the opening and closing of door can be controlled and the details of the persons who are entering and leaving are stored in cloud.

For example, the entry and exit of employees in a highly secured organization can be controlled and the details are stored in cloud so that the stored data can be monitored from remote location by their higher authority. In the same way, the entry and exit of doctors to the intensive care unit (ICU) can be controlled and the details are stored in cloud. So, if anything goes wrong in the ICU, the doctors who were present at that time can also be identified from the data available in the cloud. Real time implementation of this system can be successfully done at the places where high security is required. 


\section{REFERENCES}

[1] KuBo, "The Research of IoT based on RFID Technology", $7^{\text {th }}$ International Conference on Intelligent Computation Technology and Automation, 2014.

[2] S. Jisha, and Mintu Philip, "RFID based security platform for Internet of Things in health care environment", Online International Conference on Green Engineering and Technologies (IC-GET), 2016.

[3] Umar Farooq, Mahmood Ul Hasan, Muhammad Amar, Athar Hanif, and Muhammad Usman Asad, "RFID based security and access control system", LACSIT International Journal of Engineering and Technology., Vol. 6, No. 4, August 2014.

[4] Y. Raghavender Rao, "Automatic smart parking system using Internet of Things (IoT)", International Journal of Engineering Technology Science and Research., Vol. 4, No. 5, May 2017.

[5] Leo Louis, "Working principle of Arduino and using it as a tool for study and research", International Journal of Control, Automation, Communication and Systems (IJCACS), Vol. 1, No. 2, April 2016.
[6] Ivan Grokhotkov, ESP8266 Arduino core documentation, Release 2.4.0, May 14, 2017.

[7] T.H. Shivaraj kumar, T.A. Sriraksha, and Noor U saba, "An IoT based secured smart e-campus", International Journal of Humanities and Social Science Invention., Vol. 6, No. 3, pp.88-93, March. 2017.

[8] Elisabeth Ilie-Zudor, Zsolt Kemeny, Peter Egri, and Laszlo Monostori, "The RFID technology and its current applications", In proceedings of the Modern Information Technology in the Innovation Processes of the Industrial Enterprises-MITIP, pp. 29-36, 2006.

[9] Yalin Chen, Jue-Sam Chou, Cheng-Lun Wu, and Chi-Fong Lin, "Identifying Large-Scale RFID tags using Non-Cryptographic Approach".

[10] Mandeep Kaur, Manjeet Sandhu, Neeraj Mohan, and Parvinder S.Sandhu, "RFID Technology Principles, Advantages, Limitations \& its Applications", International Journal of Computer and Electrical Engineering, Vol. 3, No. 1, pp. 1793-8163, Feb. 2011 